\title{
Correction to: Ectopic delivery of miR-200c diminishes hepatitis C virus infectivity through transcriptional and translational repression of Occludin
}

\author{
Dalia S. Elhelw ${ }^{1} \cdot$ Sarah E. Riad $^{2} \cdot$ Heba Shawer $^{7} \cdot$ Nada El-Ekiaby $^{2} \cdot$ Ayman Salah $^{4} \cdot$ Abdelrahman Zekri $^{5}$. \\ Asma Amleh ${ }^{7}$. Gamal Esmat ${ }^{6} \cdot$ Ahmed Ihab Abdelaziz $^{2,3}$
}

Published online: 24 March 2018

(c) Springer-Verlag GmbH Austria, part of Springer Nature 2018

Correction to: Arch Virol (2017) 162:3283-3291

https://doi.org/10.1007/s00705-017-3449-3

The author would like to correct the errors in the online published article.

The affiliation of co-authors Heba Shawer and Asma Amleh should read as:

Biotechnology Program, Department of Biology, The American University in Cairo, Cairo, Egypt.

The correct email ID for corresponding author is "aihab@ngu.edu.eg“.

The original article can be found online at https://doi.org/10.1007/ s00705-017-3449-3.

Ahmed Ihab Abdelaziz

aihab@ngu.edu.eg; ahmed.abdel-aziz@guc.edu.eg

1 Department of Pharmaceutical Chemistry, German University in Cairo, New Cairo, Egypt

2 Department of Pharmacology and Toxicology, German University in Cairo, GUC New Cairo City, Main Entrance Al Tagamoa Al Khames, New Cairo 11835, Egypt

3 Present Address: School of Medicine, NewGiza University (NGU), Cairo, Egypt

4 Department of Surgery, Cairo University, Cairo, Egypt

5 Virology and Immunology Unit, Cancer Biology Department, National Cancer Institute, Cairo University, Cairo 11976, Egypt

6 Department of Endemic Medicine and Hepatology, Cairo University, Cairo 11562, Egypt

7 Biotechnology Program, Department of Biology, The American University in Cairo, Cairo, Egypt 